\title{
A mutation in CSE4, an essential gene encoding a novel chromatin-associated protein in yeast, causes chromosome nondisjunction and cell cycle arrest at mitosis
}

\author{
Sam Stoler, ${ }^{1}$ Kevin C. Keith, Kathie E. Curnick, and Molly Fitzgerald-Hayes ${ }^{2}$ \\ Department of Biochemistry and Molecular Biology, Program in Molecular and Cellular Biology, University \\ of Massachusetts at Amherst, Amherst, Massachusetts 01003 USA
}

The centromere, a differentiated region of the eukaryotic chromosome, mediates the segregation of sister chromatids at mitosis. In this study, a Saccharomyces cerevisiae chromosome mis-segregation mutant, cse4-1, has been isolated and shown to increase the nondisjunction frequency of a chromosome bearing a mutant centromere DNA sequence. In addition, at elevated temperatures the cse4-1 allele causes a mitosis-specific arrest with a predominance of large budded cells containing single $G_{2}$ nuclei and short bipolar mitotic spindles. The wild-type gene, CSE4, is essential for cell division and encodes a protein containing a domain that is $64 \%$ identical to the highly conserved chromatin protein, histone $\mathrm{H} 3$. Biochemical experiments demonstrate that CSE4p has similar DNA-binding characteristics as those of histone $\mathrm{H} 3$ and might form a specialized nucleosome structure in vivo. Interestingly, the human centromere protein, CENP-A, also contains this H3-like domain. Data presented here indicate that CSE4p is required for proper kinetochore function in yeast and may represent an evolutionarily conserved protein necessary for assembly of the unique chromatin structure associated with the eukaryotic centromere.

[Key Words: Chromosome nondisjunction; histone H3; CENP-A; chromatin; centromere; cell cycle]

Received December 13, 1994; revised version accepted January 24, 1995.

The centromere of the eukaryotic chromosome is the site of attachment of the chromatin fiber to the microtubules (MTs) of the mitotic spindle. This region directs the assembly of a nucleoprotein complex termed the kinetochore, which in turn specifies the motile behavior of sister chromatids at mitosis (Koshland 1994). The mechanism by which the centromere segregates metaphase chromosomes to opposite poles during mitosis is essential for the equal distribution of genetic material to each new daughter cell.

To date, many investigations into the structure and function of the eukaryotic centromere have been carried out in mammalian and yeast systems (Gaudet and Fitzgerald-Hayes 1989; Clarke 1990; Earnshaw and Tomkiel 1992; Bloom 1993). The large size of the mammalian centromere makes it especially amenable to detailed microscopic ultrastructural studies. In addition, several molecular components of the mammalian centromere

\footnotetext{
${ }^{1}$ Present address: Laboratory of Molecular Genetics, National Institute of Child Health and Human Development, National Institutes of Health, Bethesda, Maryland 20892 USA.

${ }^{2}$ Corresponding author.
}

have been identified, first with the aid of centromerespecific antisera from patients with CREST (calcinosis, Raynaud's phenomenon, esophageal dysmotility, sclerodactyly, and telangiectasia) autoimmune disease and later by monoclonal antibodies generated against partially purified kinetochores (Earnshaw and Rothfield 1985; Compton et al. 1991; Yen et al. 1991; Earnshaw and Tomkiel 1992). These centromere antigens, termed CENPs for centromere proteins and INCENPs for inner centromere proteins, have greatly enhanced these ultrastructural investigations. The results of these studies have yielded a model for the structure of the mammalian centromere containing the kinetochore, the central domain, and the pairing domain (Pluta et al. 1990). Innermost of these, the pairing domain is located at the points of attachment between sister chromatids. At the microtubule/centromere interface lies the kinetochore, which consists of a trilaminar plate with spindle MTs entering the outermost plate. In between the pairing domain and the kinetochore lies the central domain. This region is characterized by a highly compacted form of chromatin known as heterochromatin, which is found associated with most higher eukaryotic centromeres (Earnshaw and 
Tomkiel 1992). The DNA within this domain consists largely of a highly repetitive sequence known as alphoid satellite DNA (VanHolde 1989). The positions of several of the mammalian centromere antigens have been localized within this model, but the exact location of the CENP-A antigen is unknown because no monospecific antisera against CENP-A are available (K. Sullivan, pers. comm.). However, analysis of the CENP-A gene demonstrates that it contains a domain that is similar to the chromatin packaging protein, histone $\mathrm{H} 3$ (Sullivan et al. 1994). In addition, CENP-A has been shown to share several biochemical characteristics with $\mathrm{H} 3$ (Palmer et al. 1987). On the basis of these observations, it has been proposed that CENP-A is an integral nucleosomal component that probably plays a role in the packaging of the specialized heterochromatin found within the mammalian centromere.

Yeast is an ideal system to study the molecular genetics of centromere structure and function because of its small genome size, extensive genetics, and ability to tolerate aneuploid states for several chromosomes. Although the structure of the Schizosaccharomyces pombe centromere more closely represents those of mammalian cells, the majority of research on yeast centromeres has taken place in the Saccharomyces cerevisiae system (Clarke 1990). The structure of these centromeres is decidedly less complex than those in higher eukaryotes, as in $S$. cerevisiae there is only a single spindle microtubule attachment associated with a short segment of DNA on each chromosome. An exhaustive series of experiments have been performed to determine which DNA sequences are necessary for proper centromere function (Murphy and Fitzgerald-Hayes 1990). These studies show that the minimal functional centromere unit contains $\sim 120$ bp of CEN DNA encompassing three conserved DNA elements termed CDEI, CDEII, and CDEIII. CDEII is a 78- to 86-bp A+T-rich region flanked by CDEI (8 bp) and CDEIII, a 28-bp element with partial dyad symmetry. Nuclease digestion studies of isolated chromatin reveal a 160 - to 220 -bp protected region centered on the CEN DNA flanked by a highly phased array of positioned nucleosomes (Bloom and Carbon 1982). Further studies have shown that CDEI and CDEIII are complexed with proteins in vivo (Bram and Kornberg 1987; $\mathrm{Ng}$ and Carbon 1987; Densmore et al. 1991; Lechner and Carbon 1991). A few of the genes encoding these proteins have been cloned and characterized, but none appear to share significant homology with known mammalian centromere components (Baker and Masison 1990; Cai and Davis 1990; Doheny et al. 1993; Jiang et al. 1993a,b). To date the only structural similarity between the centromeres in these species is the presence of an array of highly phased nucleosomes at yeast centromeres and a tightly packed heterochromatin structure located around the mammalian kinetochore.

We have developed a genetic screen to isolate mutants that fail to properly segregate a genetically marked chromosome bearing a defective CEN DNA sequence (McGrew et al. 1989). We have hypothesized that the mitotic segregation of this defective chromosome could be particularly sensitive to mutations in trans-acting factors that interact with the mutant centromere DNA. This might allow for the isolation of mutations that have a more subtle effect on centromere function than those identified in previous genetic screens using a wild-type $C E N$ sequence. Here, we report the isolation of a yeast mutant, cse 4-1, that exhibits an increase in the frequency of nondisjunction of the marked chromosome at $30^{\circ} \mathrm{C}$ and arrests in mitosis at $38^{\circ} \mathrm{C}$. The wild-type gene, CSE4, encodes an essential protein that is remarkably similar in structure to human CENP-A in that it contains a histone $\mathrm{H} 3$-like domain. We present evidence that this newly identified, evolutionarily conserved protein is an integral component of yeast chromatin that might act to form a modified nucleosome core particle necessary for the assembly of centromeric chromatin.

\section{Results}

Isolation of the cse4-1 yeast mutant

We have isolated several yeast mutants using a screen designed to identify strains with defects in mitotic chromosome segregation (cse) (McGrew et al. 1989; Payne and Fitzgerald-Hayes 1993; Xiao et al. 1993). The screen uses a yeast strain that is disomic for chromosome III with one copy bearing a centromere DNA mutation. This mutant chromosome has been marked genetically to allow visual monitoring of its mitotic segregation. For the study described here, we chose the mutant centromere cen130-3, which contains a 47-bp insertion in the A+T-rich CDEII region of CEN3 (Gaudet and Fitzgerald-Hayes 1987). Yeast strain SB230 is disomic for chromosome III with one copy bearing a wild-type centromere (CEN3) and the other carrying cen130-3 flanked by URA3 and the color marker SUP11. This strain forms white colonies with occasional red sectors caused by the loss or nondisjunction of the chromosome bearing the partially defective centromere (see Materials and methods; Hieter et al. 1985). As reported previously, in wildtype cells the cen130-3 mutation causes about a 100-fold increase in chromosome mis-segregation compared with the mis-segregation frequency of chromosomes that bear the wild-type CEN3 sequence (Table 1; Gaudet and Fitzgerald-Hayes 1987). SB230 cells were mutagenized with ethyl methane sulfonate (EMS) and $\sim 80,000$ colonies were screened visually for increased mis-segregation of the marked chromosome. A set of 972-chromosomesegregation mutants have been isolated. Conditional lethality tests revealed a subset of 104 mutants that show growth defects in response to temperature changes or to low concentrations of various drugs or compounds. Further examination indicates that 17 mutants exhibit cosegregation of both the conditional lethal and chromosome mis-segregation phenotypes through three successive backcrosses.

One of these mutants, cse4-1, which is temperature sensitive at $38^{\circ} \mathrm{C}$, was chosen for further analysis. After the final backcrosses involving cse4-1 strains, the temperature-sensitive and mis-segregation phenotypes were 
Table 1. cen130-3 chromosome segregation in cse4-1 strains

\begin{tabular}{|c|c|c|c|c|}
\hline Strain & $\begin{array}{l}\text { Relevant genotype } \\
\text { (plasmid) }\end{array}$ & $\begin{array}{l}2: 0 \text { segregation } \\
\text { nondisjunction (NDJ) } \\
\left(\text { mean } \times 10^{-3} \pm \text { s.D. }\right)\end{array}$ & $\begin{array}{l}1: 0 \text { segregation } \\
\text { loss }(\mathrm{CHL}) \\
\left(\text { mean } \times 10^{-3} \pm \text { s.D. }\right)\end{array}$ & $\begin{array}{l}\text { Total mis-segregation } \\
\text { NDJ }+\mathrm{CHL} \\
\left(\text { mean } \times 10^{-3} \pm \text { S.D. }\right)\end{array}$ \\
\hline SBD1 & $\frac{\text { CSE4 CEN3 }}{\text { CSE4 Cen130-3-URA3-SUP11 }}$ & $1.3 \pm 1.8(1)$ & $1.5 \pm 0.4\langle 1\rangle$ & $2.7 \pm 1.7(1)$ \\
\hline SB701 & $\frac{\text { CSE4 CEN3 }}{\operatorname{cse} 4-1 \text { cen130-3-URA3-SUP11 }}$ & $2.6 \pm 1.2(1.4)$ & $1.3 \pm 0.9\{0.9\}$ & $3.8 \pm 0.6(1.4)$ \\
\hline SB901 & $\frac{\operatorname{cse} 4-1 \text { CEN3 }}{\operatorname{cse} 4-1 \text { cen130-3-URA3-SUP11 }}$ & $41 \pm 22(32)$ & $8.4 \pm 3.6|6\rangle$ & $47 \pm 2.5(17)$ \\
\hline SB902 & $\frac{\operatorname{cse} 4-1 \text { CEN3 (pCSE4) }}{\operatorname{cse} 4-1 \operatorname{cen} 130-3-U R A 3-S U P 11}$ & $1.7 \pm 1.0(1.3)$ & $3.5 \pm 2.5(2.3)$ & $3.1 \pm 1.2(1.1)$ \\
\hline SB903 & $\frac{\operatorname{cse} 4-1 \text { CEN3 (pRS314) }}{\operatorname{cse} 4-1 \text { cen130-3-URA3-SUP11 }}$ & $69 \pm 26(53)$ & $18 \pm 8 \quad(12)$ & $87 \pm 31 \quad(32)$ \\
\hline
\end{tabular}

All strains are diploids with one copy of chromosome III bearing the mutant centromere, cen130-3, flanked by URA3 and SUP11 and the other copy bearing the wild-type CEN3 sequence (Materials and methods). Chromosome mis-segregation frequencies were determined by the colony color assay (Materials and methods). (S.D.) The standard deviation based on three independent experiments. The numbers in parentheses are fold increases relative to wild-type backgrounds.

shown to cosegregate in the 22 tetrads examined, indicating that both phenotypes are probably caused by a mutation or mutations in a single genetic locus.

\section{The cse4-1 mutation causes increased chromosome nondisjunction}

The colony color sectoring assay was used to measure the frequency of mis-segregation of the cen 130-3 chromosome and to differentiate between chromosome loss and nondisjunction events (see Materials and methods; Hieter et al. 1985). The overall mis-segregation frequency of the cen 130-3 chromosome is elevated 17-fold in mutant cse4-1/cse4-1 (SB901) cells compared with wild-type cells. In addition, the frequency of chromosome nondisjunction is fivefold higher than chromosome loss in this mutant, suggesting that the mis-segregation phenotype observed in cse4-1 cells is probably not a result of a defect in DNA replication (Table 1). The mis-segregation phenotype of cse4-1 cells occurs in the absence of any significant increase in the frequency of mitotic recombination (data not shown). Interestingly, the mis-segregation frequency of chromosomes bearing the wild-type CEN3 sequence is elevated only 1.6-fold in cse4-1 strains, indicating that the nondisjunction phenotype caused by the cse $4-1$ allele is specific for the mutant centromere and has little effect on the segregation of wild-type chromosomes (Table 2). CSE4/cse4-1 heterozygotes grow at $38^{\circ} \mathrm{C}$ and show no increase in chromosome mis-segregation, demonstrating that the cse4-1 allele is recessive (Table 1).

cse4-1 cells arrest at $38^{\circ} \mathrm{C}$ with large buds, a single $G_{2}$ nucleus, and short bipolar spindles

Many of the $S$. cerevisiae genes required for the proper progression through the cell cycle have been characterized. Cells harboring mutations in these cell division cycle (CDC) genes arrest at specific points in the cell cycle when they are incubated at the nonpermissive temperature. By analyzing these arrest phenotypes, a detailed map of morphological changes during the yeast cell cycle has been constructed and the execution point of many of these genes has been determined (Pringle and Hartwell 1981). As shown in Table 3 , at $38^{\circ} \mathrm{C}, 85 \%$ of the cse $4-1$ cells arrest with large buds, whereas only $30 \%$ of

Table 2. CEN3 chromosome segregation in cse4-1 strains

\begin{tabular}{|c|c|c|c|}
\hline Strain & Relevant genotype & $\begin{array}{l}\text { Loss frequency } \\
(5-\mathrm{FOA})\end{array}$ & $\begin{array}{l}\text { Loss frequency } \\
\text { (quantitative mating) }\end{array}$ \\
\hline SB564 & $\frac{C S E 4 \text { CEN3 }}{C S E 4 C E N 3-U R A 3-M A T \mathbf{a}}$ & $1.2 \times 10^{-4}(1)$ & $2.8 \times 10^{-5}(1)$ \\
\hline SB964 & $\frac{\operatorname{cse4}-1 \text { CEN3 }}{\operatorname{cse4}-1 \text { CEN3-URA3-MATa }}$ & $1.3 \times 10^{-4}(1.1)$ & $4.4 \times 10^{-5}(1.6)$ \\
\hline
\end{tabular}

All strains are diploids with one copy of chromosome III bearing the wild-type centromere, CEN3, flanked by URA3 and SUP11 and the other copy bearing the wild-type CEN3 sequence (Materials and methods). Chromosome mis-segregation frequencies were determined by either the 5-FOA or quantitative mating assays and are presented as averages of two independent experiments (Materials and methods). The numbers in parentheses are fold increases relative to wild-type backgrounds. 
Table 3. Cell cycle arrest of cse4- 1 cells at $38^{\circ} \mathrm{C}$

\begin{tabular}{|c|c|c|c|c|}
\hline Strain & $\mathrm{UB}^{\mathrm{a}}$ & $\mathrm{SB}^{\mathrm{a}}$ & $\mathrm{LB}^{\mathrm{a}}$ & $\mathrm{DB}^{\mathrm{a}}$ \\
\hline $\mathrm{SB} 104(C S E 4), 30^{\circ} \mathrm{C}$ & 35 & 32 & 32 & 2 \\
\hline SB404 (cse $4-1), 30^{\circ} \mathrm{C}$ & 23 & 34 & 38 & 5 \\
\hline $\mathrm{SB} 104$ (CSE4), $38^{\circ} \mathrm{C}$ & 28 & 35 & 30 & 8 \\
\hline $\mathrm{SB} 404(\operatorname{cse} 4-1), 38^{\circ} \mathrm{C}$ & 4 & 6 & 85 & 5 \\
\hline
\end{tabular}

Samples of the indicated strain were grown at permissive temperature $\left(30^{\circ} \mathrm{C}\right)$ in YPD to early midlog phase and then transferred to the indicated temperature for $6 \mathrm{hr}$.

${ }^{a}$ Five hundred cells from each of the above cultures were scored by their morphology. The percentage of each class is shown. (UB) Unbudded cells; (SB) small budded cells (bud size smaller than one-half the diameter of the mother); (LB) large budded; (DB) cells with two buds.

wild-type cells exhibit this morphology at this temperature. As determined by DAPI staining of DNA, the large budded cse4-1 cells contain a single nucleus located near, but not through, the bud neck indicating that the cse4-1 mutation does not affect nuclear migration to the mother/daughter junction (Fig. 1). Immunofluorescence microscopy with antitubulin antibodies shows that these arrested cells invariably contain short bipolar mitotic spindles with cytoplasmic microtubule arrays extending through the bud neck, which is consistent with an arrest before the onset of anaphase (Fig. 1). FACScan analysis measuring DNA content reveals a prominent $2 \mathrm{~N}$ peak in cse $4-1$ cells at $38^{\circ} \mathrm{C}$, indicating that most cells have progressed through DNA replication (Fig. 2). In addition, the arrest phenotype of cse4-1 cells is not dependent on the action of the DNA damage checkpoint gene RAD9 (data not shown) (Weinert and Hartwell 1988). Taken together, these results demonstrate that cse4-1 cells complete DNA replication successfully and assemble mitotic spindles but are unable to progress through the cell cycle at $38^{\circ} \mathrm{C}$ because of a specific defect in mitosis.

\section{Molecular cloning of the CSE4 gene}

The wild-type CSE4 gene (Fig. 3) was cloned by transforming SB404 (cse4-1) cells with a total genomic DNA library constructed in the centromere-based vector, pYCp50 (Rose et al. 1987). Approximately 20,000 $\mathrm{Ura}^{+}$ yeast transformants (13 genome equivalents) were tested for growth on plates lacking uracil. Total yeast DNA was prepared from two transformed colonies that grew at $38^{\circ} \mathrm{C}$ and used to transform Escherichia coli strain $\mathrm{DH} 5 \alpha \mathrm{F}^{\prime}$. The two plasmids isolated from $E$. coli were found to contain identical $\sim 15-\mathrm{kb}$ yeast genomic DNA inserts by restriction enzyme digestion analysis and were termed pCL1 (Fig. 3). Subsequent experiments revealed that a $2.35-\mathrm{kb}$ ClaI fragment of $\mathrm{pCL} 1$ subcloned into the centromere-based vector pRS314 (named pRSCL1-2) rescued both the temperature-sensitive and the chromosome mis-segregation phenotypes of cse4-1 strains (data not shown) (Sikorski and Hieter 1989).

Nested deletions of the yeast DNA in pRSCL1-2 al- lowed us to localize and sequence the CSE4 gene further. The smallest deletion clone obtained has 181 bp deleted from one end of the $2.35-\mathrm{kb}$ insert and is unable to rescue the temperature-sensitive phenotype of cse4-1 cells. This result indicated that the rescuing activity is located at one end of the ClaI subclone (Fig. 3). Sequence analysis revealed a 687-bp open reading frame (ORF) starting $109 \mathrm{bp}$ from the polylinker DNA. To verify that this ORF encodes the CSE4 gene, we subcloned the 871-bp ClaIDraI fragment into pRS314 and showed that the resultant plasmid, pCSE4, completely rescues both phenotypes (Table 1; data not shown). Integrative transformation was used to demonstrate that the authentic CSE4 gene was cloned and not a low copy suppressor (see Materials and methods).

Hybridization of CSE4-specific probes to yeast chromosomes separated by pulsed field electrophoresis reveals that CSE4 is located on chromosome XI (data not shown). Computer data base searches have revealed that
SB 104
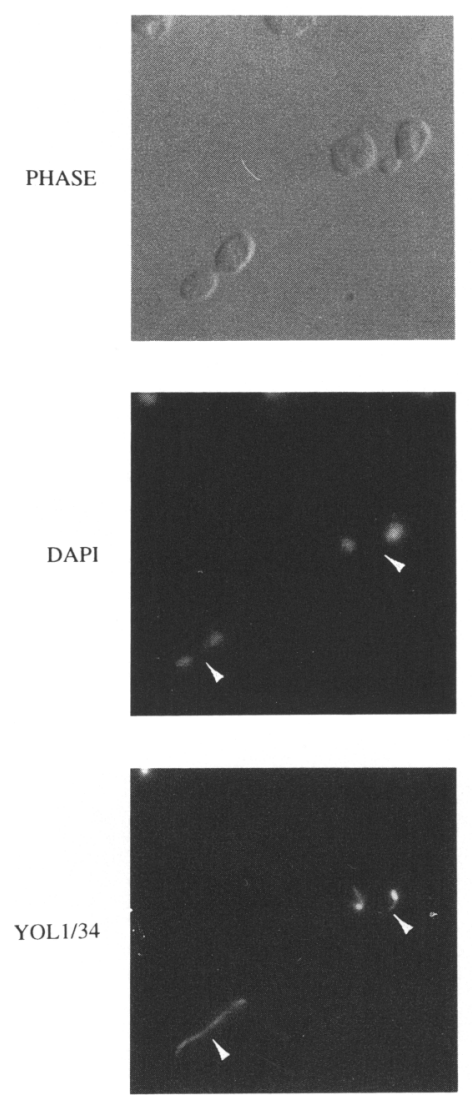

SB404
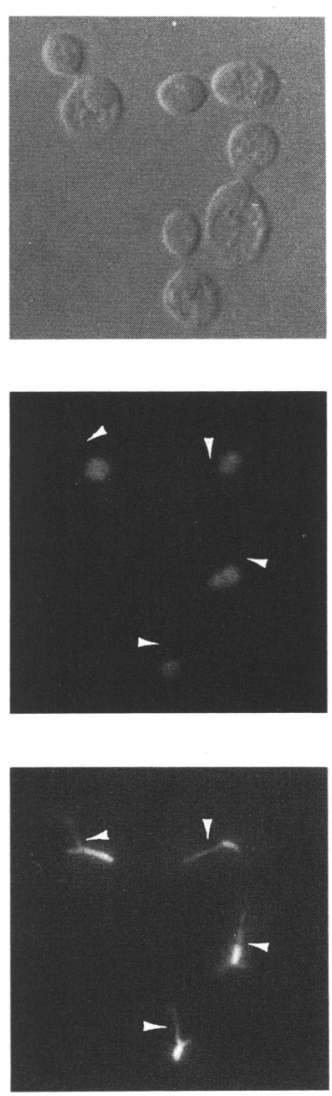

Figure 1. Micrographs of cse $4-1$ cell cycle arrest. Logarithmic cultures of SB404 (cse4-1) and SB104 (CSE4) were shifted to $38^{\circ} \mathrm{C}$ for $5 \mathrm{hr}$ and treated as described in Materials and methods. Cells were visualized with Nomarski optics or stained with DAPI to visualize DNA. Antisera YOL1/34 was used to detect mitotic spindle structure. In arrested cse4-1 cells the nuclei have migrated to the bud junction (indicated by the white arrows) and short mitotic spindles are observed with cytoplasmic microtubule arrays extending into the daughter cells. 


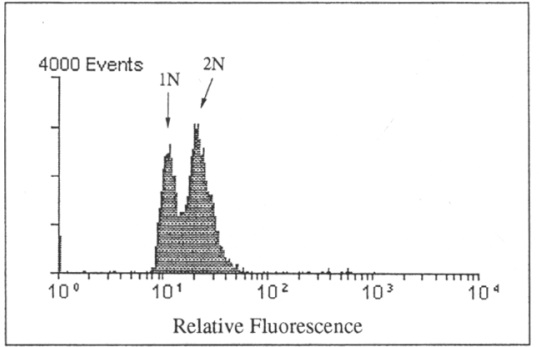

$\mathrm{SB} 10430^{\circ} \mathrm{C}$

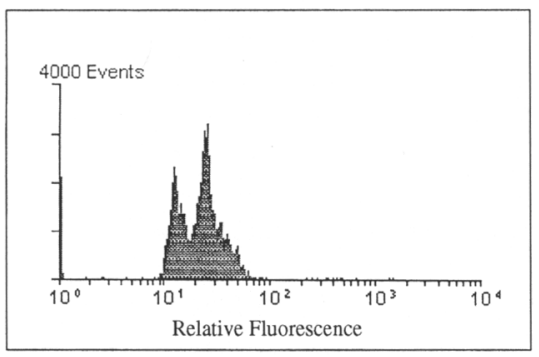

SB $10438^{\circ} \mathrm{C}$

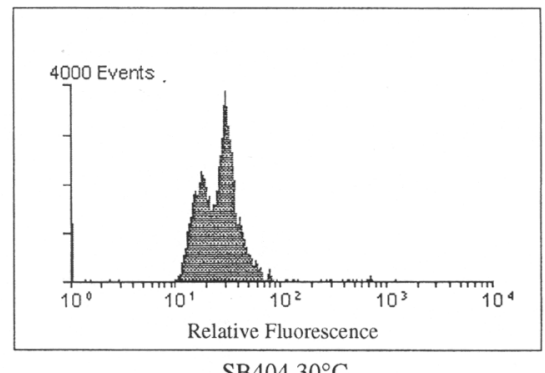

SB $40430^{\circ} \mathrm{C}$

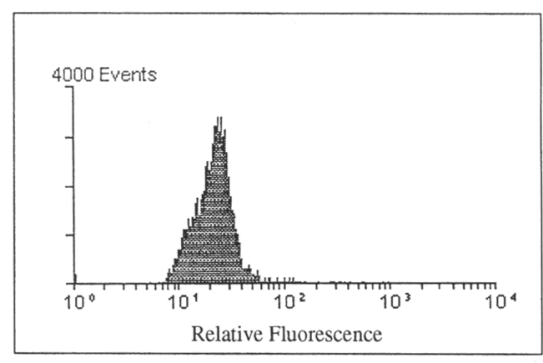

$\mathrm{SB} 40438^{\circ} \mathrm{C}$
Figure 2. FACScan analysis of cse4-1 arrested cells. SB404 (cse4-1) and SB104 (CSE4) cells were grown and fixed as described in Fig. 1, stained with propidium iodide, and subjected to FACScan analysis. Both wild-type cells and cse $4-1$ cells incubated at $30^{\circ} \mathrm{C}$ exhibit clear $1 \mathrm{~N}$ and $2 \mathrm{~N}$ peaks, whereas cse4-1 cells incubated at $38^{\circ} \mathrm{C}$ accumulate the $2 \mathrm{~N}$ peak and lack an appreciable $1 \mathrm{~N}$ peak. the carboxy-terminal 137 amino acids of CSE4 are identical to an ORF called YKL262 that was sequenced as part of the European BRIDGE project (Purnelle et al. 1993; Dujon 1994). This places CSE4 on chromosome XI just centromere distal to ELM1. Three lines of evidence demonstrate that CSE4 encodes a 229- and not a 137amino-acid protein. First, analysis shows that the sequences upstream of ORF YKL262 do not contain any elements commonly required for initiating RNA transcription, whereas a TATAA box is found 53 bp up- stream of the 229-amino-acid ORF (Fig. 4). Second, alleles with deletion or small insertion mutations in the DNA upstream from the 137-amino-acid ORF, but within the 229-amino-acid ORF, cannot rescue the temperature-sensitive phenotype of cse4-1 cells /data not shown). Third, in experiments designed to analyze the expression of CSE4p (CSE4 protein), a cassette encoding the triple influenza hemagglutinin (HAl) epitope (generous gift of B. Futcher, Cold Spring Harbor Laboratory) was inserted into the 229-amino-acid ORF at a site lo-

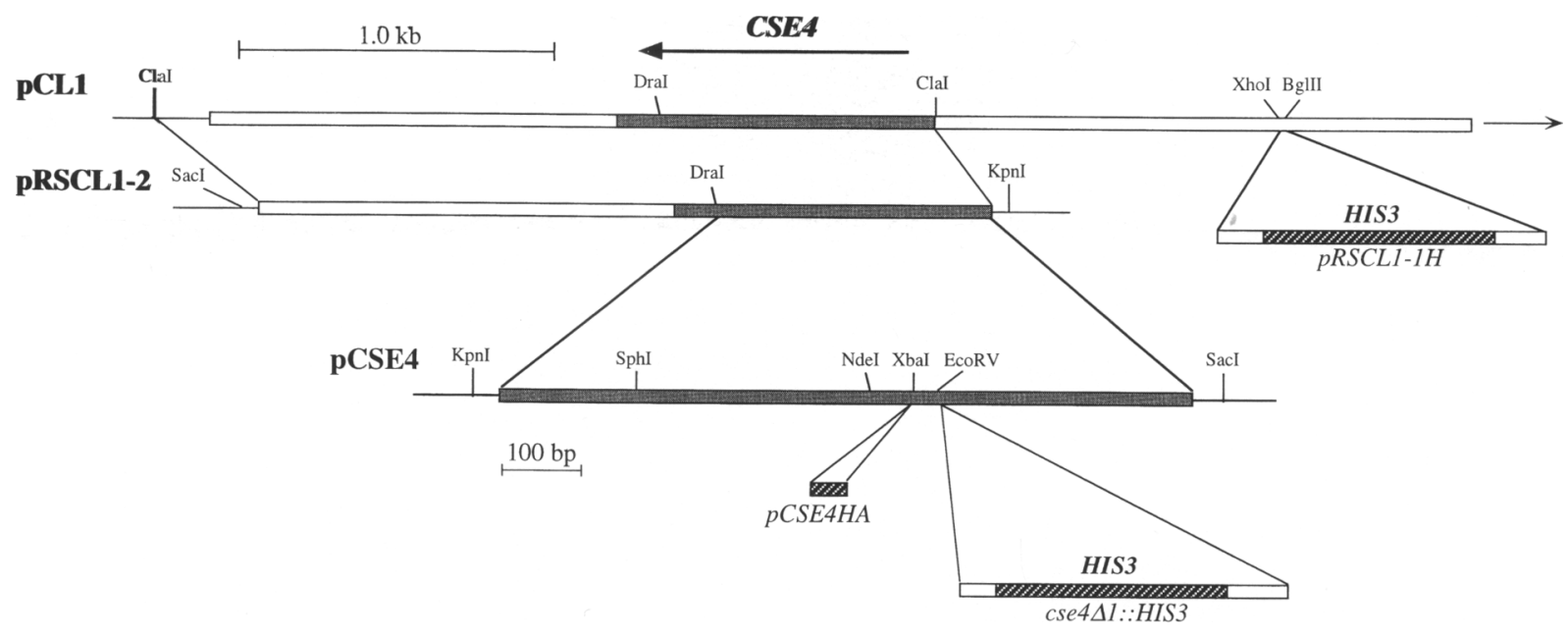

Figure 3. Genomic maps of CSE4. Shaded regions indicate yeast DNA sequenced in this study, open regions represent DNA that was sequenced in other studies; and thin lines are vector sequences from pYCp50 (pCL1) or pRS314 (pCSE4). The arrow (right) indicates that the yeast sequences in the genomic clone pCLl, continue for another $13 \mathrm{~kb}$. The bold arrow (top) indicates the direction of CSE4 transcription. The $2.35 \mathrm{~kb}$ insert in pRSCLl-2 contains sequences from the vector ClaI site at the left to the ClaI site just upstream of the CSE4 ORF. The location of the HIS3 gene in the gene disruption vector (pcse4 $\Delta 1$ ) and the integration vector (pRSCLl-1H) are shown (the HIS 3 cassette is not drawn to scale). The location of the HA tag is shown as indicated by CSE4HA. Not all restriction sites are shown. 


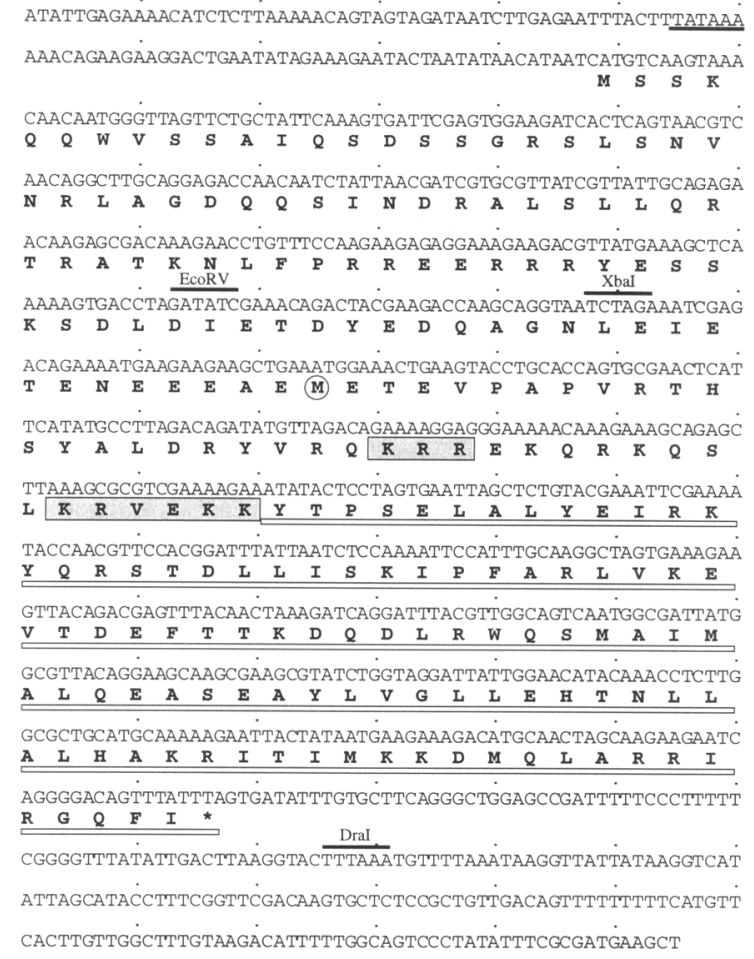

Figure 4. DNA sequence of the CSE4 gene and the predicted protein. The nucleotide and amino acid residues are numbered at left. The putative bipartite nuclear localization sequences are indicated by shaded boxes. A putative promoter element is underlined. The start of the previously published ORF is indicated by the circled methionine residue. The region of homology with the histone-fold domain of $\mathrm{H} 3$ is underlined with an open box.

cated upstream of a putative 137-amino-acid ORF (see Fig. 3). This construct, pCSE4HA, encodes a $33-\mathrm{kD}$ protein as determined by Western analysis, which is consistent with the $31-\mathrm{kD}$ size predicted from the CSE4HA sequence. These data suggest that the previously published sequence of chromosome XI contains an error upstream of ORF YKL262. The DNA sequence reported here has a single $\mathrm{G}: \mathrm{C}$ base pair insertion at nucleotide 190 of CSE4 (nucleotide 2419 of GenBank X71621) that creates the longer 229-amino-acid ORF predicted for CSE4p.

\section{CSE4 is essential for viability}

CSE4 was disrupted by inserting the HIS3 gene into the EcoRV site in the coding region in pRSCL1-2 (see Fig. 3; Materials and methods). A linear DNA fragment containing this insertion allele was used to transform a diploid yeast strain, SB560, to histidine prototrophy. The resulting CSE4/cse4::HIS3 heterozygous strain, SB961, was confirmed by Southern analysis, sporulated, and subjected to tetrad analysis. Each of the 35 tetrads examined yielded only two viable spores, all of which were $\mathrm{His}^{-}$and found to contain the wild-type CSE4 allele by Southern analysis (data not shown). Microscopic exami- nation revealed that the cse4::HIS3 spores had germinated, but could not form colonies with more than two to three cells, demonstrating that CSE4 is required for cell division. In addition, plasmid shuffle experiments confirm that CSE4 is essential for vegetative growth and not spore germination (data not shown). Subsequent experiments showed that the inviable phenotype could be rescued completely by the low copy plasmid pCSE4 (data not shown).

\section{CSE4 encodes a novel histone-like protein}

CSE4 encodes a putative 229 -amino-acid protein with a calculated molecular mass of $27 \mathrm{kD}$ and a net charge of -5 at pH 7.0 (Fig. 4). The CSE4 polypeptide contains two regions, a highly charged amino-terminal domain and a carboxy-terminal domain with striking homology to the chromatin packaging protein, histone $\mathrm{H} 3$ (Fig. 4).

The 138-residue amino terminus of CSE4p shares no significant homology with any protein found in current computer data bases but has several interesting characteristics. First, between amino acid residues 115 and 132 there is a putative bipartite nuclear localization signal that could function to target CSE4p to the nucleus (Dingwall and Laskey 1991). This domain is also highly charged, which is most apparent between residues 54 and 131 , where $>48 \%$ of the amino acids are charged at $\mathrm{pH} 7.0$ with arginine and glutamic acid residues predominating. Finally, the first 66 amino acids of CSE4p are serine rich $(>20 \%)$.

The carboxy-terminal 98 amino acids of CSE4p are $64 \%$ identical to the consensus sequence derived for the highly conserved histone $\mathrm{H} 3$ protein (Wells and McBride 1988). This region of homology is restricted to the predominantly hydrophobic "histone-fold" domain of $\mathrm{H} 3$ that has been shown to be highly ordered within the nucleosome crystal structure (Arents et al. 1991). In addition, this domain represents the minimal sequence necessary for cell viability in yeast (Mann and Grunstein 1992). The homology between CSE4p and histone H3 does not extend to the amino terminus of $\mathrm{H} 3$, which contains the post-translational modification sites that are known to be important in transcriptional regulation mediated by H3 (VanHolde 1989; Mann and Grunstein 1992). Thus, CSE4p contains a carboxy-terminal histonefold-like putative DNA-binding domain and an aminoterminal 138-amino-acid domain without significant homology to any known proteins.

Expression of the histone genes in a variety of organisms is regulated at both transcriptional and translational levels during the cell cycle with protein and mRNA levels being highest during DNA replication. Despite the similarities between CSE4p and histone H3, Northern hybridization shows that CSE4 encodes an $\sim 1.0 \mathrm{~kb}$ polyadenylated mRNA that is present at relatively constant levels throughout the cell cycle (data not shown).

\section{CSE4p is an integral component of yeast chromatin}

To examine the biochemical properties of CSE4p, the 
version containing the influenza HA epitope (CSE4HAp) was constructed by inserting DNA encoding a triple HA tag in frame into the $X b a I$ site in the amino terminus of the CSE4 ORF (Figs. 3 and 4). CSE4HAp is functional, as the CSE4HA plasmid completely rescues the lethal phenotype caused by the cse $4:$ HIS3 null allele (data not shown). Western analysis of whole cell extracts probed with the $12 \mathrm{CA} 5$ antibody reveal a $33-\mathrm{kD}$ protein in cse 4::HIS3 cells carrying the CSE4HA plasmid that is not found in wild-type cells (data not shown).

Oligomers of intact nucleosomes isolated from chromatin bind to hydroxyapatite through very tight ionic interactions between the hydroxyapatite and the phosphate groups in the DNA backbone. Buffers of increasing ionic strength can be used to remove DNA-binding proteins, including core histones, from the hydroxyapatiteDNA complex (Bloom and Anderson 1978; Simon and Felsenfeld 1979). In these experiments histones H2A and H2B characteristically elute from hydroxyapatite columns in buffers containing 0.75 to $1.0 \mathrm{M} \mathrm{NaCl}$, whereas the more tightly bound $\mathrm{H} 3 / \mathrm{H} 4$ tetramer elutes in buffers containing between 1.0 and $1.25 \mathrm{M} \mathrm{NaCl}$ (Bloom and Anderson 1978). As shown in Figure 5, CSE4HAp elutes in buffers containing 0.75 to $1.25 \mathrm{M} \mathrm{NaCl}$ with an elution peak in the fraction containing $1.0 \mathrm{M} \mathrm{NaCl}$. Also visible is a faster migrating species that probably represents a proteolytic breakdown product that contains the epitope tag and has a lower affinity for the hydroxyapatite-DNA complex. Subsequent analysis of these fractions with anti-H2B antibodies (kind gift of M. Grunstein, University of California, Los Angeles, CA) confirms that H2B elutes in the $0.75-1.0 \mathrm{M} \mathrm{NaCl}$ fractions as expected (data not shown; Bloom and Anderson 1978). These results show that CSE4HAp is biochemically similar to histone $\mathrm{H} 3$ and supports the idea that CSE4p can replace H3 in modified nucleosome structures in vivo.

CSE4p is a member of a novel class of histone H3-like proteins that includes the human centromere antigen CENP-A

Currently there are only four known genomic DNA se- quences that encode proteins with homology to histone H3. These include the yeast protein CSE4p, the mammalian kinetochore protein CENP-A, and two putative Caenorhabditis elegans proteins encoded by F54C 8.2 and F58A4.2 that were deposited in the data bases by the C. elegans Genome Sequencing project (Wilson et al. 1994). CENP-A was first identified using sera from patients suffering from CREST and shown to be a centromere-specific protein with histone-like properties. Peptide analysis of CENP-A protein isolated from bovine sperm demonstrated that the protein has a domain resembling histone H3 (Palmer et al. 1991). Recently, a partial cDNA clone corresponding to the histone-fold domain of bovine CENP-A (BCNP-A) and a full-length cDNA encoding human CENP-A (HCNP-A) have been isolated by Sullivan et al. (1994). Both CENP-A proteins contain a 92 -amino-acid domain that is $\sim 62 \%$ identical to human histone H3. The putative C. elegans proteins are $\sim 74 \%$ identical to each other overall and contain a carboxy-terminal domain that is $\sim 60 \%$ identical to $\mathrm{H} 3$. Although the carboxyl termini of CSE4p, CENP-A, and the predicted $C$. elegans proteins all resemble histone $\mathrm{H} 3$, only the sequences from C. elegans are homologous in regions outside of the histone $\mathrm{H} 3$ fold. The amino termini of CSE4p, human CENP-A, and histone H3 show no significant similarities. Even sequences derived from the non-H3-like peptides of bovine CENP-A share no amino acid homology with the amino terminus of human CENP-A.

The histone-fold domains of the five proteins are shown aligned with the consensus histone $\mathrm{H} 3$ sequence in Figure 6. The similarities of these proteins to the histone-fold domain of $\mathrm{H} 3$ are readily apparent. CSE4p, CENP-A, and the C. elegans proteins contain domains of 98 amino acids that are $64 \%, 56 \%$, and $52 \%$ identical to the histone-fold domain of $\mathrm{H} 3$. However, there are also several characteristics shared among these proteins that distinguish them from the highly conserved histone H3 molecule. Most prominent are insertions of 2-3 amino acids at the same relative positions in the CSE4p, CENPA, F54C8.2, and F58.A4.2 proteins that are not present in

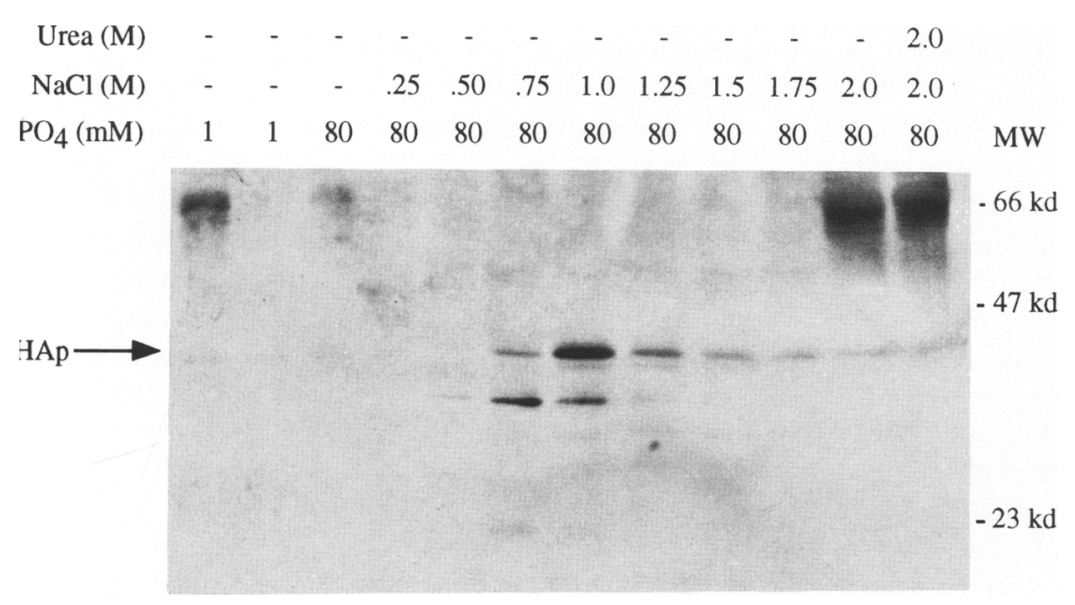

Figure 5. Western analysis of chromosomal proteins isolated by hydroxyapatite. Chromatin isolation and hydroxapatite preparations, and Western blot protocols are described in Materials and methods. Chromosomal proteins were eluted in the buffers indicated, precipitated, and subjected to gel electrophoresis. The Western blot shown here was probed with anti-HA antisera, 12CA5. The CSE4HA protein is similar to histone $\mathrm{H} 3$ in that it elutes primarily in the $1.0 \mathrm{M} \mathrm{NaCl}$ fractions. Western analysis of the same fractions probed with antisera against histone $\mathrm{H} 2 \mathrm{~B}$ reveal that $\mathrm{H} 2 \mathrm{~B}$ elutes from hydroxyapatite in the $0.75-1.0 \mathrm{M} \mathrm{NaCl}$ fractions as expected. The numbers at right represent approximate molecular masses in $\mathrm{kD}$. 
Figure 6. Comparison of the histone-fold regions of the CSE4, bovine CENP-A (BCNP-A), human CENP-A (HCNP-A) proteins, the $C$. elegans ORFs, and the histone $\mathrm{H} 3$ consensus sequence. Numbers above the sequences indicate amino acid positions in the full-length $\mathrm{H} 3$ protein. Shaded regions represent residues that are identical to $\mathrm{H} 3$. Two to three amino acid insertions in the H3-like sequences are shown (O). The tryptophan residue conserved in the CENP-A and CSE4 proteins, which replaces the conserved phenylalanine residue at position number 84 of $\mathrm{H} 3$, is indicated (star). Positions where 3 of 5 residues are identical, but differ from $\mathrm{H} 3$, are indicated with open boxes.
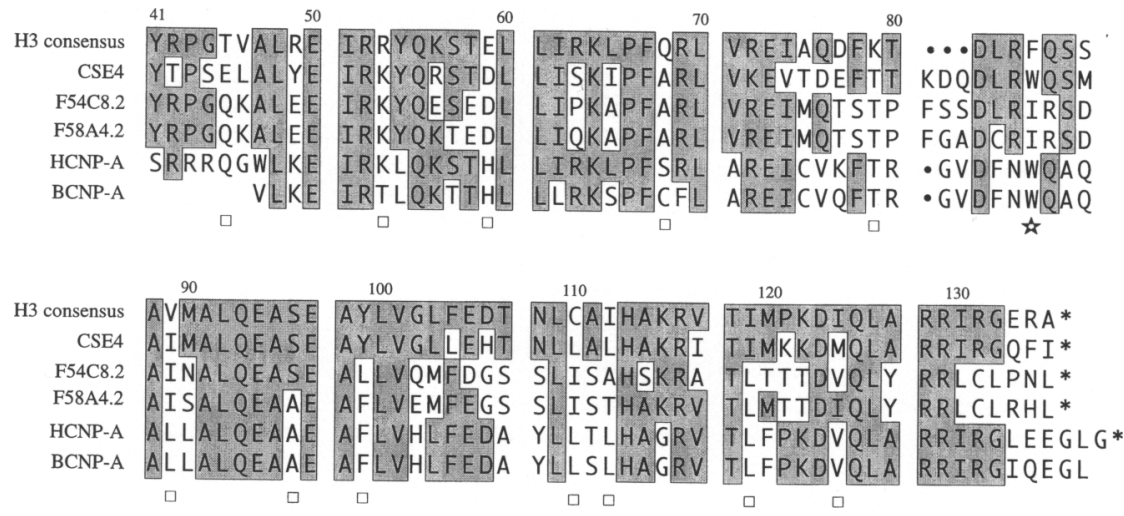

histone H3. In addition, at 13 positions in the aligned sequences, at least three of the five histone-like proteins share identical amino acid residues that are not present in histone $\mathrm{H} 3$ (Fig. 6). Most notable of these is the replacement of a highly conserved phenylalanine residue located at position 84 of H3 (CSE4p 178) with a tryptophan. This amino acid, which is conserved among the CENP-A proteins and CSE4p, is significant because no core histone sequenced to date contains a tryptophan residue at any position (VanHolde 1989). Clearly, these CENP-A-like proteins represent a new class of highly divergent histone H3-like proteins found in organisms from yeast to humans.

\section{Discussion}

The advent of visual assays to measure chromosome ploidy in yeast has enabled several groups to isolate an extensive set of mutants that are defective in chromosome transmission. In many cases the wild-type genes that complement these chromosome segregation mutations have been cloned. As expected, genes that encode previously identified components of the mitotic spindle or DNA metabolism pathways have been recovered. In addition, a number of previously unidentified genes have also been isolated, including some genes that encode components of the yeast kinetochore (Doheny et al. 1993; Goh and Kilmartin 1993). The approach used in our study is specifically designed to recover mutants that exhibit increased aberrant segregation of a full-length chromosome bearing a partially defective $C E N$ sequence. This screen could be especially sensitive to mutations in gene products that function in the assembly or function of the centromere. We have used this approach to characterize novel genes that have not been reported in other chromosome segregation screens (Payne and FitzgeraldHayes 1993; Xiao et al. 1993). In this paper we describe the cloning and characterization of CSE4, the latest gene isolated using this genetic strategy and show that it encodes a novel histone H3-like protein necessary for proper progression through mitosis.

Nondisjunction events result from the segregation of both replicated sister chromatids to the same pole at anaphase. A subset of nondisjunction events are caused by failure of the centromeres of paired sister chromatids to interact properly with the microtubules of the spindle. Previous studies demonstrate that mutations in chromosomal centromere DNA increase the frequency of chromosome nondisjunction more than loss as a direct result of the defect in the chromatin structure associated with the centromere (Saunders et al. 1988; McGrew et al. 1989; Densmore et al. 1991). In contrast, mutations affecting DNA replication cause an increase in the frequency of chromosome loss. Several lines of evidence support the idea that CSE4p functions in chromosome segregation as opposed to DNA replication. First, the arrest phenotypes exhibited by cse $4-1$ cells are consistent with a specific cell division cycle block occurring after the mitotic spindle is assembled and before the onset of sister chromatid separation at anaphase. This arrest phenotype resembles that of $c t f 13-30$ cells, which are known to have a defect in an essential kinetochore protein (Doheny et al. 1993). Second, the cse4-1 arrest phenotype is $R A D 9$ independent and the arrested cells have a $\mathrm{G}_{2}$ DNA content indicating that cse4-1 cells have completed DNA replication before arrest. Finally, the cse4-1 allele causes a large increase in the frequency of chromosome nondisjunction of the cen130.3 chromosome while having only a slight effect on chromosome loss. Taken together, these data establish an essential role for CSE4p in mitotic chromosome segregation and suggest that it may play an important role in centromere structure or function.

The fact that CSE4p contains a histone H3-like domain is intriguing and indicates that it most likely plays a role in the assembly of a specialized form of chromatin. The nucleosome structure of eukaroytic chromatin, and the role that each of the four core histones play in this structure, continue to be the subject of intense study. This basic chromatin packaging mechanism is ubiquitous in all eukaryotic nuclei studied to date. Indeed, the arginine-rich histones, $\mathrm{H} 3$ and $\mathrm{H} 4$, are two of the most evolutionarily conserved proteins found in nature, differing at only a few amino acid positions from yeasts to 
mammals (Wells and McBride 1988). Interestingly, the region of homology between CSE4p and $\mathrm{H} 3$ encompasses the highly ordered hydrophobic domain of $\mathrm{H} 3$ known as the histone-fold, which is the region found to be ordered in the nucleosome in vitro (Arents et al. 1991). Deletion experiments in yeast demonstrate that virtually the entire amino-terminal 40 amino acids of histone $\mathrm{H} 3$, which contains the majority of post-translational modification sites, are dispensable for vegetative growth (Mann and Grunstein 1992). However, deletions removing only a few residues within this domain are lethal. The amino terminus of CSE4p is 94 amino acids longer than the amino terminus of $\mathrm{H} 3$ and shows no homology to any protein sequences in the current data bases. Therefore, CSE4p contains a carboxyl terminus that closely resembles the domain of $\mathrm{H} 3$ known to be required for nucleosome assembly in vivo and an amino terminus that presumably has some yet to be identified function.

We have shown that CSE4p and histone H3 have similar physical properties when isolated from chromatin complexes. This observation supports the intriguing possibility that CSE4p replaces H3 in a specialized nucleosome structure. Recent studies directed by Mitchell Smith, using a temperature-sensitive allele of histone $\mathrm{H} 4$ that arrests in mitosis (hhf1-20), strongly supports this hypothesis. The $h h f 1-20$ allele encodes a protein containing two amino acid changes in the histone-fold domain of histone $\mathrm{H} 4$ (M. Smith, pers. comm.). A hunt for high copy suppressors of the temperature-sensitive phenotype of hhf1-20 cells yielded several isolates of a gene identical to CSE4 (P. Yang and M. Smith, unpubl.). Subsequent experiments demonstrated that the hhf1-20 phenotype could not be rescued by overexpression of histone $\mathrm{H} 3$ alone. Together, these results suggest that CSE4p participates with $\mathrm{H} 4$ in the assembly of a novel chromatin structural unit in vivo.

The lack of monospecific antisera to mammalian CENP-A has hindered its exact localization within the mammalian centromere. However, its similarities to histone $\mathrm{H} 3$ strongly suggest that it functions in centromeric heterochromatin. The alphoid satellite sequences found within this region are assembled into an ordered array of nucleosomes (Zhang et al. 1983; VanHolde 1989). Interestingly, nuclease digestion studies have revealed ordered arrays of phased nucleosomes associated with the flanking sequences surrounding the yeast centromere, suggesting that at least some structural features of the eukaryotic centromere have been conserved through evolution (Bloom and Carbon 1982). In addition, elegant in vivo protection experiments have demonstrated that the nuclease-protected region within the yeast centromere is highly resistant to ionic conditions known to disrupt most loose DNA-protein complexes (Bloom et al. 1984). Only under ionic conditions known to disrupt nucleosomal core particles does the yeast centromere region become sensitive to nuclease digestion. In addition, depletion of either histone $\mathrm{H} 4$ or $\mathrm{H} 2 \mathrm{~B}$ has also been shown to disrupt this nuclease-protected region (Saunders et al. 1990). These observations strongly suggest a prominent role for nucleosomal chromatin in the structure and function of the eukaryotic centromere. Indeed, a model proposed by Bloom et al. (1989) incorporates a modified nucleosomal core particle as the structural foundation for the formation of the yeast kinetochore. Interestingly, the cse4-1 allele isolated in this study has little or no effect on the function of wild-type centromeres, but has a large effect on the function of the mutant centromere cen130-3, which is 47-bp longer than wild-type CEN3. The "synthetic" phenotype created by the combination of these cis-and trans-acting mutations supports the hypothesis that CSE4p interacts in some way with the DNA of the centromere. Experiments designed to test this possibility are currently underway.

Considering the structural and biochemical similarities between CSE4p and CENP-A, and the apparent sister chromatid separation defect in cse4-1 cells, it is tempting to speculate that these proteins have similar roles in centromere function in yeast and mammalian cells. Unfortunately, yeast experiments designed to rescue either temperature-sensitive or null alleles of cse 4 by high expression of human CENP-A have been unsuccessful (K. Keith, S. Stoler, and M. Fitzgerald-Hayes, unpubl.). In addition, transient expression experiments in mammalian cells using epitope-tagged constructs of CSE4p show that CSE4HAp is transported into the mammalian nucleus but does not localize to the centromere (K. Sullivan, unpubl.). However, the DNA sequences underlying the centromere are some of the most rapidly evolving elements in the eukaryotic genome and therefore, these results do not rule out conclusively the possibility that CSE4p and CENP-A actually perform the same cellular function in both species. For instance, both CSE4p and CENP-A could form specialized nucleosomes in centromeric heterochromatin through interactions involving the carboxy-terminal histone-fold domains, while also interacting with different non-nucleosomal proteins through their dissimilar amino-terminal regions. In this way the chromatin structure underlying the centromere is conserved between species, whereas the divergent amino termini of the proteins remain available for interactions with proteins that are species-specific for each organism's centromere.

Clearly, defects in chromatin structure at sites other than the centromere can cause chromosome mis-segregation. For example, it is known that disruption of the chromatin structure at yeast telomeres is associated with an increase in chromosome loss (Lundblad and Szostak 1989; Sandell and Zakian 1994). In addition, several genetic loci, including telomeres, are repressed transcriptionally by a mechanism known as "silencing." This silencing phenomenon is known to require nucleosome components (Johnson et al. 1992). Although recent evidence indicates that telomeric silencing is unaffected in cse 4 mutants (E. Wiley and V. Zakian, unpubl.), CSE4p could play a role in the repression or activation of other loci that are required for accurate chromosome segregation. It is clear that additional experiments will be needed to further define the connection between CSE4p and chromosome segregation. The results of these investigations will provide new insights into the flexibility of 
the nucleosome model of chromatin and could help elucidate the relationship between chromosome segregation and the structural foundations of centromeric chromatin.

\section{Materials and methods}

Media, strains, and DNA manipulations

Media for yeast growth and sporulation were described previously (Sherman et al. 1983). Rich media for yeast cultures (YPD) contains $2 \%$ glucose, $1 \%$ peptone, and $0.5 \%$ yeast extract (Difco) supplemented with $50 \mathrm{mg} /$ liter filter-sterilized tryptophan. Color media contain $0.6 \%$ Difco yeast nitrogen base, $0.5 \%$ casamino acids, $2 \%$ glucose, $50 \mu \mathrm{g} / \mathrm{ml}$ tryptophan, $30 \mu \mathrm{g} /$ $\mathrm{ml} \mathrm{uracil,} \mathrm{and} 4.5 \mu \mathrm{g} / \mathrm{ml}$ of adenine. 5-Fluoro-orotic acid 15 FOA) medium contains $0.5 \mathrm{mg} / \mathrm{ml}$ in minimal media supplemented with $20 \mu \mathrm{g} / \mathrm{ml}$ of uracil and amino acid supplements as needed. Yeast strains used in this study are listed in Table 4. All yeast strains were grown at $30^{\circ} \mathrm{C}$ unless indicated otherwise. Genetic analysis was performed by standard methods described previously (Sherman et al. 1983). DNA manipulations were performed as described (Maniatis et al. 1983). Total yeast DNA was isolated by the glass-bead breakage method as described previously (Hoffman and Winston 1987). Total yeast RNA was isolated by hot phenol extraction (Domdey et al. 1984). Poly(A) ${ }^{+}$ RNA was purified with a Poly(A) Quick Extraction Kit (Stratagene) according to the manufacturer's instructions. For cell cycle Northern analyses, strain R11-4c (bar1-1) cells were synchronized and RNA purified as described previously (Price et al. 1991|. RNA and DNA were transferred either to GeneScreen (DuPont) or Nitrocellulose (Micron Separations, Inc.) membranes by standard techniques. Gel-purified DNA fragments were isolated from either agarose or polyacrylamide gels and ${ }^{32} \mathrm{P}$-labeled using a NEBlot kit (New England Biolabs) according to the manufacturer's instructions. About $5 \times 10^{5} \mathrm{cpm}$ of labeled probe was used in each hybridization reaction. All restriction enzymes were purchased from New England Biolabs Inc., and used as specified by the vendor.

Table 4. Strains used in this study

\begin{tabular}{|c|c|c|}
\hline Strain & Relevant genotype & Source \\
\hline AGll & $\begin{array}{l}\text { MATa/MATa ade2-101/ade2-101 HIS3/his3-11,15 LEU2/leu2-3 trp1 } 9901 / \operatorname{trp} 1 \Delta 901 \\
\text { ura3-52/ura3-52 }\end{array}$ & A. Gaudet (unpubl.) \\
\hline SBDl & 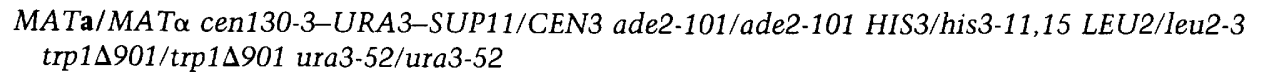 & this study \\
\hline SB230 & $\begin{array}{l}\text { MATa/MATa cen130-3-URA3-SUP11/CEN3 ade2-101 his3-11,15 lys2-801 trp1 } 1901 \text { ura3-52 } \\
\text { (disomic for chromosome III) }\end{array}$ & this study \\
\hline SB104 & MATa ade2-101 leu2-3 trp1 $\Delta 901$ ura3-52 & this study \\
\hline SB106 & MATa cen130-3-URA3-SUP11/CEN3 ade2-101 his3-11,15 leu2-3 lys2-801 trp1 9001 ura3-52 & this study \\
\hline SB451 & $\begin{array}{l}\text { MATa cen130-3-URA3-SUP11/CEN3 ade2-101 his3-11,15 leu2-3 lys2-801 trp1D901 ura3-52 } \\
\text { cse4-1 }\end{array}$ & this study \\
\hline SB404 & 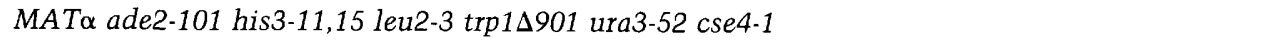 & this study \\
\hline SB409 & MAT $\alpha$ ade2-101 his3-11,15 lys2-801 trp14901 ura3-52 cse4-1 & this study \\
\hline SB163 & 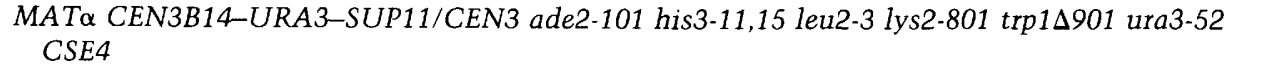 & this study \\
\hline SB463 & $\begin{array}{l}\text { MATa CEN3B14-URA3-SUP11/CEN3 ade2-101 his3-11,15 leu2-3 lys2-801 trp1 } 9901 \text { ura3-52 } \\
\text { cse4-1 }\end{array}$ & this study \\
\hline YJJ53 & 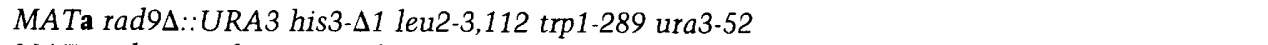 & YGSC \\
\hline SB441 & 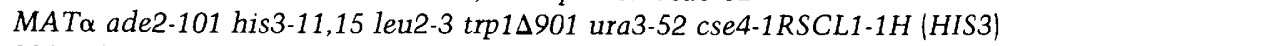 & this study \\
\hline SB560 & 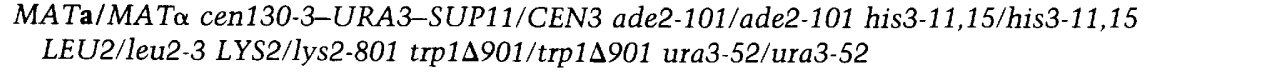 & this study \\
\hline SB961 & $\begin{array}{l}\text { MATa/MATa cen130-3-URA3-SUP11/CEN3 ade2-101/ade2-101 his3-11,15/his3-11,15 } \\
\text { LEU2/leu2-3 LYS2/lys2-801 trp1D901/trp1 } 901 \text { ura3-52/ura3-52 CSE4/cse4::HIS3 }\end{array}$ & this study \\
\hline SB472 & MATa ade2-101 his3-11,15 trp1 901 ura3-52 cse4::HIS3 (pCSE4) & this study \\
\hline SB473 & MATa ade2-101 his3-11,15 trp1 4901 ura3-52 cse4::HIS3 (pCSE4HA) & this study \\
\hline SB176 & MATa ade2-101 his3-11,15 trp1s901 ura3-52 rho $^{-}$ & this study \\
\hline SB476 & MATa ade2-101 his3-11,15 trp14901 ura3-52 cse4::HIS3 rho- (pCSE4HA) & this study \\
\hline R11-4c & MATa bar1-1 leu2 ura3 & R. Baker (unpubl.) \\
\hline SB901 & 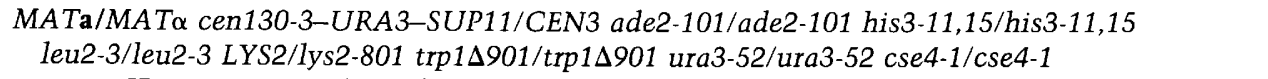 & this study \\
\hline SB902 & same as SB901 + pCSE4 $(T R P 1)$ & this study \\
\hline SB903 & same as SB901+pRS314 (TRP1) & this study \\
\hline SB701 & 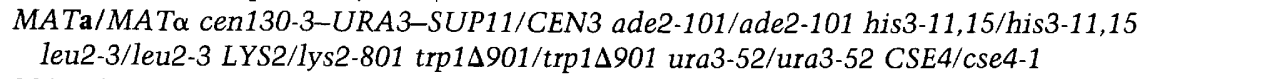 & this study \\
\hline SB520 & 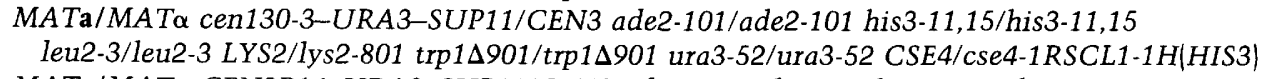 & this study \\
\hline SB964 & 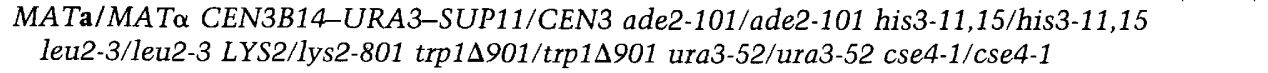 & this study \\
\hline SB564 & 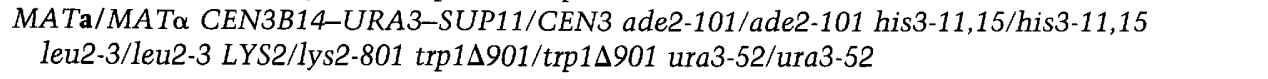 & this study \\
\hline
\end{tabular}




\section{Disome construction and mutagenesis}

The disome yeast strain used in this screen was constructed as described previously with the following modifications (McGrew et al. 1989). The parental diploid strain AG11 was transformed with a CEN3 substitution vector containing the cen130-3 mutant centromere. cen130-3 contains a 47-bp insertion in CDEII (Gaudet and Fitzgerald-Hayes 1987). The resultant strain SBD1 was confirmed by Southern analysis and subjected to similar genetic manipulations as those described previously to obtain a strain that is disomic for chromosome III (McGrew et al. 1989). In these cells one copy of chromosome III bears the wild-type CEN3 sequence and the other copy carries the cen 130-3 centromere flanked by $U R A 3$ and the color marker SUP11. Colonies formed by this strain contain white and red sectors attributable to the loss or nondisjunction of the marked chromosome. EMS (Kodak) mutagenesis was performed with $28 \%$ cell survival. Strains that showed an increase in chromosome mis-segregation were analyzed genetically as described previously to obtain mutants that show cosegregation of both the chromosome mis-segregation and the conditional lethal phenotypes (Xiao et al. 1993).

\section{Chromosome mis-segregation assays}

The mitotic segregation of SUP11-marked chromosomes bearing cen 130-3 centromeres was monitored using the color colony assay (Hieter et al. 1985). SUP11 suppresses partially the red color phenotype of ade2-101 yeast cells. Hence, in a diploid homozygous for the ade2-101 allele, one copy of SUP11 suppresses partially the red color to form homogeneous pink colonies. Two copies of SUP11 suppress fully this phenotype resulting in white colonies. Strains where SUP11 is linked genetically to a chromosome that is mitotically unstable form colonies that contain red, pink, and white sectors. Red and pink sectors arise from chromosome loss $(1: 0)$ events and nondisjunction $(2: 0)$ events result in red/white sectors. Half-sectored colonies represent mis-segregation events that occurred at the first division after plating. The number of half-sectored colonies divided by the total number of mostly pink colonies plated represents the mis-segregation frequency of the SUP11-bearing chromosome. In addition, the number of red/pink and red/white half-sectored colonies is used to determine the frequency of chromosome loss or nondisjunction, respectively. The mis-segregation data for cen130-3 chromosomes was collected as follows. In each assay, three mostly pink colonies were picked from color media plates and $\sim 3000$ cells were spread onto large $(150 \times 15 \mathrm{~mm})$ color media plates, incubated for 4 days at $30^{\circ} \mathrm{C}$ and then overnight at $4^{\circ} \mathrm{C}$. At least three independent assays were performed to monitor the segregation of cen130-3 chromosomes in each wild-type and cse4-1 strain.

Mis-segregation events involving chromosome III containing wild-type CEN3 occur infrequently and cannot be measured practically by the color colony assay. However, these events can be quantitated using two more sensitive methods, the 5FOA and the quantitative mating assays (Clarke and Carbon 1980; Boeke et al. 1984). 5-FOA is toxic to cells that are prototrophic for uracil; therefore, only cells that cannot synthesize uracil are able to grow on media containing this compound. Haploid strains SB463 (cse4-1) and SB163 (CSE4) bearing a wild-type CEN3 sequence (CEN3B14) flanked by $U R A 3$ and SUP11 were constructed by homologous recombination as described previously (McGrew et al. 1989). SB463 was crossed with SB404 to generate SB964 (CEN3B14-URA3-SUP11 cse4-1/ cse4-1) and SB163 was crossed to SB104 to generate SB564 (CEN3B14-URA3-SUP11 CSE4/CSE4). Strains SB964 and
SB564 were grown overnight in media lacking uracil and about $10^{6}$ cells were plated onto $100 \times 15-\mathrm{mm} 5$-FOA plates. In parallel, 100-300 cells were plated onto rich media lacking 5-FOA to determine viability. The mis-segregation frequencies were determined by dividing the number of $\mathrm{Ura}^{-}$colonies by the total number of viable cells plated. The quantitative mating assay depends on the ability of cells that are aneuploid $(2 \mathrm{~N}-1)$ for chromosome III to mate with MATa or MAT $\alpha$ tester strains. Briefly, strains SB564 and SB964 are grown overnight in nonselective media, allowed to mate with an excess of the appropriate tester strain and then plated to select for only those cells that have mated. The number of colonies from the total number of cells challenged represents the fraction of cells that have lost a copy of chromosome III. Both the quantitative mating and the 5-FOA assays enable one to measure a single chromosome loss event in $\leqslant 10^{5}$ divisions. However, these assays are unable to distinguish between chromosome loss and nondisjunction.

\section{Cellular and nuclear morphology}

Appropriate yeast strains were grown to a $\mathrm{OD}_{660}$ of $\sim 0.5$ in liquid YPD at $30^{\circ} \mathrm{C}$. An equal volume of YPD at $46^{\circ} \mathrm{C}$ was added and the culture transferred to $38^{\circ} \mathrm{C}$ for $5 \mathrm{hr}$. Cells were then either fixed in ethanol for phase-contrast microscopy or fixed in formaldehyde for fluorescence microscopy as described (Pringle et al. 1990). DNA was visualized by staining with $4^{\prime}, 6^{\prime}$-diamidino-2-phenylindole (DAPI; Sigma). DNA content of cells stained with propidium iodide (Gerring et al. 1990) was determined using a FACScan flow cytometer (Becton Dickinson) equipped with a doublet discriminator. Microtubule structures including mitotic spindles were visualized by indirect immunofluorescence microscopy using rat monoclonal YOL1/34 as the primary antiserum and a rhodamine-conjugated goat-antirat IgG (Cappel) as the secondary antibody. For the RAD9 experiment, a double mutant cse4-1 rad9::URA3 strain was constructed by crossing YJJ53 (rad9::URA3) to SB409 and the resultant diploid subjected to tetrad analysis to obtain the proper double mutant haploid. The strain was then subjected to the nonpermissive temperature and found to arrest with a phenotype identical to that of cse4-1 cells.

\section{Cloning and sequence analysis of CSE4}

SB404 (cse4-1) cells were transformed with a low-copy-number YCp50 yeast genomic library (American Type Culture Collection) using the lithium acetate method and incubated at $38^{\circ} \mathrm{C}$ for 5 days on media lacking uracil. $\mathrm{Ura}^{+}$transformants were restreaked to confirm their ability to grow at the nonpermissive temperature. Positive strains were then mated with SB451 (cse4-1), a haploid containing the cen130-3 chromosome, to produce the diploid strains needed to monitor the chromosome mis-segregation phenotype. Plasmids that rescued both the temperature-sensitive and the chromosome mis-segregation phenotypes were recovered from yeast by shuttle transformation into $E$. coli and the genomic DNA fragments were subcloned into appropriate pRS vectors for further analysis (Sikorski and Hieter 1989).

A $2.35-\mathrm{kb}$ ClaI fragment from pCL1 containing $\sim 2.0 \mathrm{~kb}$ of yeast genomic DNA and 375 bp of YCp50 vector sequence (ClaI-BamHI) was subcloned into pRS314 and shown to rescue both phenotypes completely. Nested deletions extending from the KpnI site in the polylinker into the yeast DNA were constructed using exonuclease III and tested for the ability to rescue the temperature-sensitive phenotype of yeast strain SB404. None of the deletion mutants rescued this phenotype indicating that the rescuing activity is located near one end of the insert. 
A region of 1018 bp of yeast DNA was sequenced by the dideoxynucleotide chain termination method using the deletion clones as templates. The other strand was sequenced using DNA oligonucleotides designed from the sequence of the first strand as primers. The 871-bp ClaI-DraI fragment containing the CSE4 ORF and 184 bp of flanking DNA was cloned into pRS314. This plasmid, termed pCSE4, was shown to rescue both phenotypes.

Analysis of nucleic acid and protein sequences was performed with GCG software (Genetics Computer Group, Inc., Madison, WI) on a Sun Microsystems Sparcstation and on the BLAST server at the National Center for Biotechnology Information (NCBI, National Institutes of Health, Bethesda, MD). The GenBank and EMBL data bases were searched using TFASTA, FASTA, and BLASTP programs. A multiple sequence alignment was constructed using the progressive alignment method of Feng and Doolittle (1987) using the PILEUP command in GCG. The CSE4 ORF was searched for protein motifs in the PROSITE Dictionary of Protein Sites and Patterns using the MOTIFS command in GCG. DNA sequences were manipulated using DNA Inspector IIe and the Gene Construction Kit (Textco, Inc., Lebanon, $\mathrm{NH}$ ) software on a Macintosh computer.

\section{Gene disruption and integration mapping}

A null allele of CSE4 was generated by the one-step gene disruption method (Rothstein 1983). An 8-bp BglII site was generated at the EcoRV site in the CSE4 ORF by linker mutagenesis. The 1.1-kb BamHI fragment from pYDpH (Berben et al. 1991) containing the HIS3 gene was cloned into this BglII site to disrupt the CSE4 ORF by simple insertion resulting in pcse $4 \Delta 1$. The 1.45-kb ApoI fragment from pcse4 $\Delta 1$ containing the HIS3 gene flanked by yeast CSE4 sequences was used to transform the diploid strain SB560 to His ${ }^{+}$. Selected histidine prototrophs were confirmed by Southern blot hybridization to have a heterozygous disruption of the CSE4 locus. One such strain, SB961, was sporulated and tetrad analysis was performed by standard methods (Sherman et al. 1983).

To confirm that the cloned DNA represented the authentic CSE4 gene, the HIS3 gene was cloned into a BglII site located in the genomic DNA $1.2 \mathrm{~kb}$ upstream of the CSE4 ORF in a flanking subclone (pRSCL1-1). This construct, pRSCL1-1H, was digested with ClaI and used to transform SB404 (cse4-1) to histidine prototrophy. The structure of this genomic integration was confirmed by Southern hybridization. The resultant haploid, SB441, was crossed to SB106 (CSE4) and the resultant diploid, SB520, was subjected to tetrad analysis. In 21 of 22 complete tetrads examined the temperature-sensitive phenotype segregated with histidine prototrophy, demonstrating that the two loci are genetically linked. To map the gene to a yeast chromosome, AG11 cells were prepared as described for pulsed field gel electrophoresis analysis on a CHEF apparatus (Owl Scientific) and probed with CSE4-specific DNA fragments by Southern hybridization.

\section{Epitope tag and protein expression}

For Western and subsequent biochemical analyses, an epitopetagged version of CSE4p was constructed. Plasmid pCSE4 DNA was digested with NotI and BamHI, treated with Klenow DNA polymerase, and religated to destroy the unique NotI site and remove one of the three $X b a I$ sites. The resultant plasmid, pCSE4NB, was digested partially with $\mathrm{XbaI}$ and ligated to annealed oligonucleotides $\left(5^{\prime}\right.$-CTAGGCGGCCGC- $\left.3^{\prime}\right)$ containing $X b a I$ staggered ends and a NotI site. In this way, a construct containing a unique NotI site in the CSE4 ORF was obtained and a 111-bp NotI fragment encoding three HA epitopes was cloned into this site. The resultant plasmid, pCSE4HA, encodes a protein of 270 amino acids. This plasmid was shuffled into SB472 (cse4::HIS3) to make strain SB473 and shown to rescue completely the inviable phenotype. Total proteins isolated from SB473 and analyzed by Western blot using the 12CA5 antibody and an ECL Western analysis kit (Amersham) reveal a 33-kD species in SB473 cells that is not observed in wild-type strains.

\section{Chromatin isolation and hydroxyapatite fractionation}

Yeast chromatin was isolated by the method of Szent-Gyorgyi and Isenberg (1983) with the following modifications. Strains SB476 (cse4::HIS3; pCSE4HA) and SB176 (CSE4) were made rho $^{-}$as described and grown in 1 liter of YPD to a $\mathrm{OD}_{660}$ of $\sim 1.8$. Cells were harvested by centrifugation, washed once in $\mathrm{Sl}$ buffer [1.4 M sorbitol, $40 \mathrm{mM}$ F-(2-hydroxyethyl)piperazine-N'(2-ethanesulfonic acid) (Na-HEPES) $0.5 \mathrm{~mm} \mathrm{MgCl}_{2}, 1.0 \mathrm{~mm}$ phenylmethylsulfonyl fluoride (PMSF) (pH 7.5)] and resuspended in $10 \mathrm{ml}$ of $\mathrm{S} 1$ buffer plus $0.5 \%$ of $\beta$-mercaptoethanol. Lyticase (Sigma) and Zymolyase 100T (ICN Biomedicals Inc.) were added to a final concentration of $800 \mathrm{U} / \mathrm{ml}$ and $10 \mu \mathrm{g} / \mathrm{ml}$, respectively, and the solution was incubated with gentle agitation at $30^{\circ} \mathrm{C}$ for $90 \mathrm{~min}$. All subsequent steps were carried out on ice unless specified otherwise. After spheroplasting, two volumes of S2 buffer [1.4 M sorbitol, $20 \mathrm{mM}$ Na-PIPES, $0.5 \mathrm{mM} \mathrm{MgCl}, 1.0 \mathrm{mM}$ PMSF (pH 6.5)] were added to the suspension and centrifuged for $10 \mathrm{~min}$ at $2000 \mathrm{~g}$. The pelleted spheroplasts were resuspended in $10 \mathrm{ml}$ of $18 \%$ Ficoll buffer [18\% Ficoll 400 (wt/vol), $20 \mathrm{~mm}$ Na-PIPES, $0.5 \mathrm{mM} \mathrm{MgCl}_{2}, 1.0 \mathrm{mM}$ PMSF (pH 6.5)] and resuspended vigorously with a vortex mixer. The resulting lysate was homogenized with 15 strokes of a Dounce homogenizer on ice and layered over $10 \mathrm{ml}$ of glycerol-Ficoll buffer $[20 \%$ glycerol (vol/vol), 7\% Ficoll 400 (wt/vol), $20 \mathrm{~mm} \mathrm{Na-PIPES,} 0.5 \mathrm{~mm}$ $\mathrm{MgCl}_{2}, 1.0 \mathrm{~mm}$ PMSF (pH 6.5)] in 30-ml Corex tubes and centrifuged at $4^{\circ} \mathrm{C}$ for $40 \mathrm{~min}$ at $25,000 \mathrm{~g}$. The pelleted nuclei were washed once in $10 \mathrm{ml}$ of $18 \%$ Ficoll buffer and repelleted as above. The chromatin was made insoluble with the addition of $10 \mathrm{ml}$ of PIPES buffer [5.0 mM Na-PIPES, $0.5 \mathrm{mM} \mathrm{MgCl}_{2}, 1.0 \mathrm{mM}$ PMSF ( $\mathrm{pH} 6.5$ ) ], followed by vigorous vortexing and incubation at $38^{\circ} \mathrm{C}$ with gentle agitation for $10 \mathrm{~min}$. The suspension was centrifuged at $4^{\circ} \mathrm{C}$ for $15 \mathrm{~min}$ at $12,000 \mathrm{~g}$. The supernatant was removed by aspiration and the pellet resuspended in $5 \mathrm{ml}$ of 10 $\mathrm{mM} \mathrm{NaPO}_{4}(\mathrm{pH}$ 7.0).

The chromatin pellet was resuspended by vigorous $(3 \mathrm{~min}$ at the highest setting) vortexing and resolubilized by sonication for 15-sec bursts at half power (Fisher Sonic Dismembrator model 300). The hydroxyapatite elution method of Bloom and Anderson (1978) was used to analyze this chromatin fraction with the following modifications. Two grams of a slurry of hydroxyapatite was sedimented by centrifugation at $1000 \mathrm{~g}$ for 2 min in a tabletop centrifuge, washed once with $1 \mathrm{mM} \mathrm{NaPO}$ (pH 7.0), and sedimented again. Four milliliters of the prepared chromatin was applied to the hydroxyapatite, the mixture converted to a slurry with a sterile spatula and gentle vortexing, incubated on ice for $2 \mathrm{~min}$, and centrifuged as before. The supernatant was transferred to a new tube and stored at $-20^{\circ} \mathrm{C}$. $\mathrm{NaCl}$ and urea fractions were taken by mixing the indicated buffer with the hydroxyapatite-chromatin and treated as above. Ten percent of the fractions was precipitated with tricloro-acetic acid, and resuspended in sample buffer for analysis on $15 \%$ SDS-PAGE in preparation for Western blotting.

\section{Acknowledgments}

We thank Kevin Sullivan, Mitchell Smith, and Virginia Zakian for the use of reagents and/or unpublished results, Bruce 
Futcher for a plasmid containing the HA epitope tag, Michael Grunstein for the anti-H2B antibodies, and Dawn Cishek for help with FACScan analysis. We also thank Arlene Gaudet, Herwig Ponstigl, Jeff McGrew, and Kerry Bloom for helpful discussions. This work was supported by a U.S. Public Health Service grant (GM32257) and a Research Career Development Award (GM00528) from the National Institutes of Health to M. F.-H.

The publication costs of this article were defrayed in part by payment of page charges. This article must therefore be hereby marked "advertisement" in accordance with 18 USC section 1734 solely to indicate this fact.

\section{Note added in proof}

The sequences described in this paper have been deposited to the GenBank data library under accession no. U20327.

\section{References}

Arents, G., R.W. Burlingame, B.-C. Wang, W.E. Love and E.N. Moudrianakis. 1991. The nucleosomal core histone octamer at 3.1 angstrom resolution: A tripartite protein assembly and left-handed superhelix. Proc. Natl. Acad. Sci. 88: 1014810152.

Baker, R.E. and D.C. Masison. 1990. Isolation of the gene encoding the Saccharomyces cerevisiae centromere-binding protein CP1. Mol. Cell. Biol. 10: 2458-2467.

Berben, G., J. Dumont, V. Gilliquet, P.-A. Bolle, and F. Hilger. 1991. The YDp plasmids: A uniform set of vectors bearing versatile gene disruption cassettes for Saccharomyces cerevisiae. Yeast 7: 475-477.

Bloom, K. 1993. The centromere frontier: Kinetochore components, microtubule-based motility, and the CEN-value paradox. Cell 73: 621-624.

Bloom, K., A. Hill, M. Kenna, and M. Saunders. 1989. The structure of a primitive kinetochore. Trends Biochem. Sci. 14: $223-227$.

Bloom, K.S. and J.N. Anderson. 1978. Fractionation and characterization of chromosomal proteins by the hydroxyapatite dissociation method. J. Biol. Chem. 253: 4446-4450.

Bloom, K.S. and J. Carbon. 1982. Yeast centromere DNA is in a unique and highly ordered structure in chromosomes and small circular minichromosomes. Cell 29: 305-317.

Bloom, K.S., E. Amaya, and E. Yeh. 1984. Chromatin conformation of yeast centromeres. J. Cell Biol. 99: 1559-1568.

Boeke, J.D., F. LaCroute, and G.R. Fink. 1984. A positive selection for mutants lacking orotidine-5' - phosphate decarboxylase activity in yeast: 5 -Fluoro-orotic acid resistance. Mol. \& Gen. Genetics 197: 345-346.

Bram, R.J. and R.D. Kornberg. 1987. Isolation of a Saccharomyces cerevisiae centromere DNA-binding protein, its human homolog, and its possible role as a transcription factor. Mol. Cell. Biol. 7: 403-409.

Cai, M. and R.W. Davis. 1990. Yeast centromere binding protein $\mathrm{CBF} 1$, of the helix-loop-helix protein family, is required for chromosome stability and methionine prototrophy. Cell 61: 437-446.

Clarke, L. 1990. Centromeres of budding and fission yeasts. Trends Genet. 6: 150-154.

Clarke, L. and J. Carbon. 1980. Isolation of a yeast centromere and construction of functional small circular chromosomes. Nature 287: 504-509.

Compton, D.A., T.J. Yen, and D.W. Cleveland. 1991. Identifica- tion of novel centromere/kinetochore-associated proteins using monoclonal antibodies generated against human mitotic chromosome scaffolds. J. Cell Biol. 112: 1083-1097.

Densmore, L., W.E. Payne, and M. Fitzgerald-Hayes. 1991. In vivo genomic footprint of a yeast centromere. Mol. Cell. Biol. 11: 154-165.

Dingwall, C. and R.A. Laskey. 1991. Nuclear targeting sequences-A consensus? Trends Biochem. Sci. 16: 478-481.

Doheny, K.F., P.K. Sorger, A.H. Hyman, S. Tugendreich, F. Spencer, and P. Hieter. 1993. Identification of essential components of the $S$. cerevisiae kinetochore. Cell 73: 761-774.

Domdey, H., B. Apostol, R.-J. Lin, A. Newman, E. Brody, and J. Abelson. 1984. Lariat structures are in vivo intermediates in yeast pre-mRNA splicing. Cell 39: 611-621.

Dujon, B., D. Alexandraki, B. Andre, W. Ansorge, V. Baladron, J.P.G. Baleesta, A. Banrevi, P.A. Bolle, M. Bolotin-Fukuhara, P. Bossier et al. 1994. Complete sequence of yeast chromosome XI. Nature 369: 371-378.

Earnshaw, W.C. and N. Rothfield. 1985. Identification of a family of human centromere proteins using autoimmune sera from patients with scleroderma. Chromosoma 91: 313-321.

Earnshaw, W.C. and J.E. Tomkiel. 1992. Centromere and kinetochore structure. Curr. Opin. Cell Biol. 4: 86-93.

Feng, D.-F. and R.F. Doolittle. 1987. Progressive sequence alignment as a prerequisite to correct phylogenetic trees. I. Mol. Evol. 25: 351-360.

Gaudet, A. and M. Fitzgerald-Hayes. 1987. Alterations in the adenine-plus-thymine-rich region of CEN3 affect centromere function in Saccharomyces cerevisiae. Mol. Cell. Biol. 7: 68-75.

- 1989. The function of centromeres in chromosome segregation. In The eukaryotic nucleus: Molecular biochemistry and macromolecular assemblies (ed. P. Stauss and S. Wilson), pp. 845-881. Telford Press, London, UK.

Gerring, S.L., F. Spencer, and P. Hieter. 1990. The CHL (CTF1) gene product of Saccharomyces cerevisiae is important for chromosome transmission and normal cell cycle progression in G2/M. EMBO J. 9: 4347-4358.

Goh, P.-Y. and J.V. Kilmartin. 1993. NDC10: A gene involved in chromosome segregation in Saccharomyces cerevisiae. I. Cell Biol. 121: 503-512.

Hieter, P., C. Mann, M. Snyder, and R.W. Davis. 1985. Mitotic stability of yeast chromosomes: A colony color assay that measures nondisjunction and chromosome loss. Cell 40: 381-392.

Hoffman, C.S. and F. Winston. 1987. A ten-minute DNA preparation from yeast efficiently releases autonomous plasmids for transformation of Escherichia coli. Gene 57: 267-272.

Jiang, W., J. Lechner, and J. Carbon. 1993a. Isolation and characterization of a gene (CBF2) specifying a protein component of the budding yeast kinetochore. I. Cell Biol. 121: 513-519.

Jiang, W., K. Middleton, H.-J. Yoon, C. Fouquet, and J. Carbon. 1993b. An essential yeast protein, CBF5p, binds in vitro to centromeres and microtubules. Mol. Cell Biol. 13: 48844893.

Johnson, L.M., G. Fisher-Adams, and M. Grunstein. 1992. Identification of a non-basic domain in the histone $\mathrm{H} 4 \mathrm{~N}$-terminus required for repression of the yeast silent mating loci. EMBO 1. 11: 2201-2209.

Koshland, D. 1994. Mitosis: Back to the basics. Cell 77: 951954.

Lechner, J. and J. Carbon. 1991. A $240 \mathrm{kd}$ multisubunit protein complex, CBF3, is a major component of the budding yeast centromere. Cell 64: 717-725.

Lundblad, V. and J.W. Szostak. 1989. A mutant with a defect in telomere elongation leads to senescence in yeast. Cell 
57: 633-643.

Maniatis, T., E.F. Fritsch, and J. Sambrook. 1983. Molecular cloning: A laboratory manual. Cold Spring Harbor Laboratory, Cold Spring Harbor, New York.

Mann, R.K. and M. Grunstein. 1992. Histone H3 N-terminal mutations allow hyperactivation of the yeast GAL1 gene in vivo. EMBO I. 11: 3297-3306.

McGrew, J.T., Z. Xiao, and M. Fitzgerald-Hayes. 1989. Saccharomyces cerevisiae mutants defective in chromosome segregation. Yeast 5: 271-284.

Murphy, M. and M. Fitzgerald-Hayes. 1990. Cis- and trans-acting factors involved in centromere function in Saccharomyces cerevisiae. Mol. Microbiol. 4: 329-336.

$\mathrm{Ng}$, R. and J. Carbon. 1987. Mutational and in vitro proteinbinding studies on centromere DNA from Saccharomyces cerevisiae. Mol. Cell. Biol. 7: 4522-4534.

Palmer, D.K., K. O'Day, M.H. Wener, B.S. Andrews, and R.L. Margolis. 1987. A $17-\mathrm{kD}$ centromere protien (CENP-A) copurifies with nucleosome core particles and with histones. I. Cell Biol. 104: 805-815.

Palmer, D.K., K. O'Day, H.L. Trong, H. Charbonneau, and R.L. Margolis. 1991. Purification of the centromere-specific protein CENP-A and demonstration that it is a specific histone. Proc. Natl. Acad. Sci. 88: 3734-3738.

Payne, W.E. and M. Fitzgerald-Hayes. 1993. A mutation in $P L C 1$, a candidate phosphoinositide-specific phospholipase $\mathrm{C}$ gene from Saccharomyces cerevisiae, causes aberrant mitotic chromosome segregation. Mol. Cell. Biol. 13: 43514364.

Pluta, A.F., C.A. Cooke, and W.C.Earnshaw. 1990. Structure of the human centromere at metaphase. Trends Biochem. Sci. 15: $181-185$.

Price, C., K. Nasmyth, and T. Schuster. 1991. A general approach to the isolation of cell cycle-regulated genes in the budding yeast, Saccharomyces cerevisiae. I. Mol. Biol. 218: $543-556$.

Pringle, J.R. and L.H. Hartwell. 1981. The Saccharomyces cerevisiae cell cycle. Cold Spring Harbor Laboratory, Cold Spring Harbor, New York.

Pringle, J.R., R.A. Preston, A.E.M. Adams, T. Stearns, D.G. Drubin, B.K. Haarer, and E.W. Jones. 1990. Fluorescence microscopy methods for yeast. Methods Cell Biol. 31: 419-435.

Purnelle, B., H. Tettelin, L. Van Dyck, J. Scala, and A. Goffeau. 1993. The sequence of a $17.5 \mathrm{~kb}$ DNA fragment on the left arm of yeast chromosome XI identifies the protein kinase gene ELM1, the DNA primase gene PRI2 a new gene encoding a putative histone and seven new open reading frames. Yeast 9: 1379-1384

Rose, M.D., P. Novick, J.H. Thomas, D. Botstein, and G.R. Fink. 1987. A Saccharomyces cerevisiae genomic plasmid bank based on a centromere-containing shuttle vector. Gene 60: $237-243$.

Rothstein, R.J. 1983. One-step gene disruption in yeast. Methods Enzymol. 101: 202-211.

Sandell, L.L. and V.A. Zakian. 1994. Loss of a yeast telomere: Arrest, recovery, and chromosome loss. Cell 75: 729-739.

Saunders, M., M. Fitzgerald-Hayes, and K. Bloom. 1988. Chromatin structure of altered yeast centromeres. Proc. Natl. Acad. Sci. 85: 175-179.

Saunders, M.I., E. Yeh, M. Grunstein, and K. Bloom. 1990. Nucleosome depletion alters the chromatin structure of Saccharomyces cerevisiae centromeres. Mol. Cell. Biol. 10: 5721-5727.

Sherman, F., G. Fink, and J.B. Hicks. 1983. Methods in yeast genetics. Cold Spring Harbor Laboratory, Cold Spring Harbor, New York.
Sikorski, R.S. and P. Hieter. 1989. A system of shuttle vectors and yeast host strains designed for efficient manipulation of DNA in Saccharomyces cerevisiae. Genetics 122: 19-27.

Simon, R.H. and G. Felsenfeld. 1979. A new procedure for purifying histone pairs $\mathrm{H} 2 \mathrm{~A}+\mathrm{H} 2 \mathrm{~B}$ and $\mathrm{H} 3+\mathrm{H} 4$ from chromatin using hydroxyapatite. Nucleic Acids Res. 6: 689-695.

Sullivan, K.F., M. Hechenberger, and K. Masri. 1994. Human CENP-A contains a histone $\mathrm{H} 3$ related histone fold domain that is required for targeting to the centromere. I. Cell Biol. 127: $581-592$.

VanHolde, K.E. 1989. Chromatin. Springer Verlag, New York.

Weinert, T.A. and L.H. Hartwell. 1988. The RAD9 gene controls the cell cycle response to DNA damage in Saccharomyces cerevisiae. Science 241: 317-241.

Wells, D. and C. McBride. 1988. A comprehensive compilation and alignment of histones and histone genes. Nucleic Acids Res. (Suppl.) 17: r311-r346.

Wilson, R., R. Ainscough, K. Anderson, C. Berks, J. Bonfield, J. Barton, M. Connell, T. Copsey, J. Cooper et al. 1994. 2.2 Mb of contiguous nucleotide sequence from chromosome III of C. elegans. Nature 368: 32-38.

Xiao, Z., J.T. McGrew, A.J. Schroeder, and M. Fitzgerald-Hayes. 1993. CSE1 and CSE2, two new genes required for accurate mitotic chromosome segregation in Saccharomyces cerevisiae. Mol. Cell. Biol. 13: 4691-4702.

Yen, T.J., D.A. Compton, D. Wise, R.P. Zinkowski, B.R. Brinkley, W.C. Earnshaw, and D.W. Cleveland. 1991. CENP-E, a novel human centromere-associated protein required for progression from metaphase to anaphase. EMBO I. 10: 12451254.

Zhang, X.-Y., F. Fittler, and W. Horz. 1983. Eight different highly specific nucleosome phases on alpha-satellite DNA in the African green monkey. Nucleic Acids Res. 11: 42874307. 


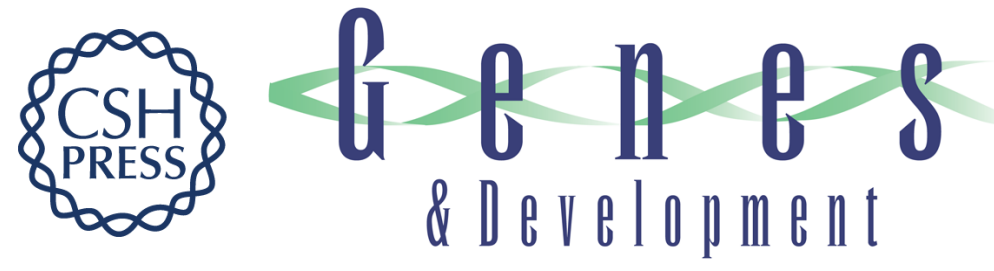

\section{A mutation in CSE4, an essential gene encoding a novel chromatin-associated protein in yeast, causes chromosome nondisjunction and cell cycle arrest at mitosis.}

S Stoler, K C Keith, K E Curnick, et al.

Genes Dev. 1995, 9:

Access the most recent version at doi:10.1101/gad.9.5.573

References This article cites 58 articles, 20 of which can be accessed free at: http://genesdev.cshlp.org/content/9/5/573.full.html\#ref-list-1

License

Email Alerting Receive free email alerts when new articles cite this article - sign up in the box at the top Service right corner of the article or click here.

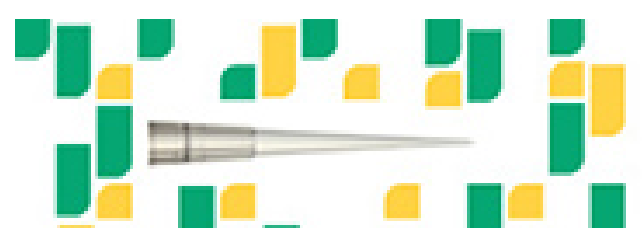

Focused on your science. 